\title{
nature/methods
}

\section{Author Correction: CRISPR-assisted detection of RNA-protein interactions in living cells}

Wenkai Yi, Jingyu Li (D), Xiaoxuan Zhu, Xi Wang Dig, Ligang Fan, Wenju Sun, Linbu Liao DD, Jilin Zhang (D), Xiaoyu Li, Jing Ye, Fulin Chen, Jussi Taipale, Kui Ming Chan (D), Liang Zhang (iD and Jian Yan (iD

Correction to: Nature Methods https://doi.org/10.1038/s41592-020-0866-0, published online 22 June 2020.

In the version of this article initially published, gray and green were reversed in the key for Fig. $2 \mathrm{~d}$. The error has been corrected in the PDF and HTML versions of the article.

Published online: 22 January 2021

https://doi.org/10.1038/s41592-021-01067-w

(c) The Author(s), under exclusive licence to Springer Nature America, Inc. 2021

\section{Publisher Correction: DeepCell Kiosk: scaling deep learning-enabled cellular image analysis with Kubernetes}

Dylan Bannon, Erick Moen, Morgan Schwartz (D), Enrico Borba, Takamasa Kudo, Noah Greenwald (D), Vibha Vijayakumar, Brian Chang, Edward Pao, Erik Osterman, William Graf and David Van Valen (D)

Correction to: Nature Methods https://doi.org/10.1038/s41592-020-01023-0, published online 4 January 2021.

In the version of this article initially published, the order of the layers was reversed in Fig. 1a in the items labeled Image(s) and Output, leading to black square outlines overlaid on the images. In Fig. 1b, lettering reading $2.4 \mathrm{~GB}$ and $240 \mathrm{MB}$ (left panel) and $2.4 \mathrm{~GB}$ (right panel) should have read $2.4 \mathrm{Gbs}, 240 \mathrm{Mbs}$ and $2.4 \mathrm{Gbs}$, respectively. The errors have been corrected in the PDF and HTML versions of the article.

Published online: 13 January 2021

https://doi.org/10.1038/s41592-021-01059-w

() The Author(s), under exclusive licence to Springer Nature America, Inc. 2021

\section{Publisher Correction: Method of the Year: spatially resolved transcriptomics}

Vivien Marx

Correction to: Nature Methods https://doi.org/10.1038/s41592-020-01033-y, published online 6 January 2021.

In the version of this article initially published, the MERFISH image caption indicated that the image shows mouse brain. In fact, the image is of human cancer cells. The error has been corrected in the PDF and HTML versions of the article.

Published online: 19 January 2021

https://doi.org/10.1038/s41592-021-01065-y

๑) Springer Nature America, Inc. 2021 